\title{
Determination of Polycyclic aromatic hydrocarbons (PAHs) in Yerba-maté herbal drink
}

\author{
Christian Nwankwo ${ }^{1}$, Stephen Barton ${ }^{1}$, and Heba Ghazal ${ }^{1, *}$ \\ ${ }^{1}$ Kingston University, School of Pharmacy and Chemistry, Kingston Upon Thames KT1 2EE, \\ United Kingdom
}

\begin{abstract}
Yerba-maté (Y-M), known as llex-paraquariensis is traditional South American herbal drink that is consumed as an aqueous extract from the Y-M leaves. This drink is thought to have long-term health benefits and thus it has recently gained more popularity. However, health hazards of polyaromatic hydrocarbons (PAHs) deposited in Y-M during drying process has been linked to the development of different types of cancer in particular oesophageal cancer. The current study developed and validated an extraction and analytical method to determine the presence of one of the PAH compounds, namely; benzo(b)fluoranthene [Bbf] as an indicator for the $\mathrm{PAH}(\mathrm{s})$ occurrence in $\mathrm{Y}-\mathrm{M}$ in commercial samples of the dried leaves. Since the expected level of contamination with this compound is at trace level thus a sensitive and selective analytical method was needed. Gas Chromatography-Mass Spectrometry GC-MS method was developed using selected ion monitoring (SIM) with split-less mode focusing on 126 ion and 252 ion (main) for [Bbf]. The content of [Bbf] using different extraction methods was found in a range 0.02 to $0.09 \mu \mathrm{g} / \mathrm{g}$. GC-MS results indicated a good repeatability of the peak area with strong correlation and linearity between mean peak area and concentration from the calibration curve. Soxhlet extraction using hexane as a solvent gave the highest yield of [Bbf] concentration. However, ultrasonic extraction using hot distilled water as a solvent is recommended as it better simulates the way of making and drinking.
\end{abstract}

\section{Introduction}

Yerba- maté (Y-M) is scientifically known as llex-paraquariensis or Aquifoliaceae. It is a plant originally found in subtropical-regions of Southern-America including Uruguay, Paraguay, Argentina and Brazil [1]. The aqueous-extract from Y-M leaves is a herbal drink prepared as beverages under four different names: maté-tea, terere, maté-cocido and chimarrioao. Traditionally about $50 \pm 0.1 \mathrm{~g}$ of the dried leaves of $\mathrm{Y}-\mathrm{M}$ are placed inside gourd container and hot or cold water is poured for maté-tea or Terere preparation,

\footnotetext{
* Corresponding author: H.Ghazal@kingston.ac.uk
} 
respectively. Water is added multiple of times up to approximately 1.5 litres. The rate of drinking Y-M has risen far beyond $1 \mathrm{~L}$ daily among millions of people in the countries mentioned above. This drink is consumed for its social-role and as a source of caffeine and other health benefits. Many studies have indicated that drinking Y-M extracts has long term health benefits such as antioxidative and anti-inflammatory properties, weight reduction, decrease in cholesterol, increase in energy and control of diabetes. Other studies reported that it has hepatoprotective, diuretic and antimicrobial properties and the ability to act as a central nervous system stimulant [2].

Although dinking Y-M has beneficial effects mentioned above, one of the health hazards associated with its consumption includes high prevalence of oesophageal-cancer (EC) which is recorded as the eighth most-common cancer and the sixth most prevalent cause of cancer death globally. It is believed that the technique of drying Y-M possibly contributes to the development of carcinogenic compounds called polycyclic-aromatic hydrocarbons (PAHs). Other possible causes of EC include long-term mucosal ulceration as a result of thermal injury from intake of hot Y-M. PAHs are group of compounds that contain fused aromatic rings without substituents or hetero-atoms attached. They have high melting and boiling points and are nonpolar and highly lipophilic. PAHs are formed from incomplete burning of organic constituents that includes coal, fossil fuels, vegetation, oil and tobacco.

Establishing sources of PAHs in dry Y-M is the initial strategy, in reducing PAHs which in turns could lead to the reduction in the incidence of EC in people consuming this drink. Processing of Y-M involves slow drying, using wood-smoke that takes roughly 8-24 hours and this can lead to the accumulation of PAHs in the Y-M especially in mass production for commercial purposes. Furthermore, Y-M processing techniques such as drying, aging and blanching could result in the deposition of PAHs into this drink. Benzo(a)pyrene (Bap) has been the most studied PAH compound and several research studies have indicated that it has the highest carcinogenic effect to humans. PAHs are hydrophobic compounds that are absorbed quickly when ingested into to the gastrointestinal tract (GI) or into the lungs via inhalation. It is believed that they alter cellular membrane and enzymatic reactions that occur in human cells while others suggested that PAHs are strong immune-suppressants and they are easily disperse in body tissues upon exposure within minute-hours and leads to the formation of metabolic activated carcinogens. This carcinogenic compound binds to deoxyguanosine residue of the DNA to form DNA adducts. DNA adduct is considered the main event of carcinogenicity and mutagenicity of PAHs in human beings. Studies indicated that high intake of food that contain PAHs during pregnancy such as benzo(b)fluoranthene, chrysene, benzo(a)anthracene and benzo(a)pyrene lead to birth imperfection and a reduction in body weight. In 2008, the review of the risk assessment of PAHs by the European Food Safety Authority recommended the use of the sum of four different concentrations for four different PAH compounds ( $\mathrm{PAH} 4) 0.5 \mu \mathrm{g} / \mathrm{kg}$ as the bench mark which includes, Benzo(a)pyrene [Bap], benzo(b)fluoranthene(Bbf), chrysene and benzo(a)anthracene as the marker for contamination in food [3].

In this study, Benzo(b)fluoranthene (Figure 1) was investigated as a marker for the occurrence of PAHs in samples of dry Y-M. Since the expected level of contamination with this compound is at trace level thus a sensitive analytical method was developed and employed to measure the level of [Bbf] in sample of dried Y-M. 


\section{Materials}

Standard reference of Benzo(b)fluoranthene, cyclohexane and hexane HPLC grade and anhydrous sodium sulphate were purchased from Sigma- Aldrich UK. A commercial sample from ground dry Y-M obtained from Brazil.

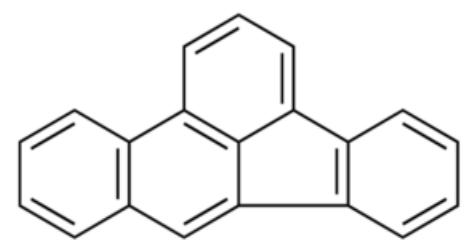

Fig. 1. The chemical structure of Benzo[b]fluoranthene (MW 252, CAS 205-99-2).

\subsection{Experimental}

\subsubsection{Effect of extraction method}

a. Infusion of Yerba-maté in hot distilled water

Hot Y-M was prepared in a similar way in which it is prepared and consumed traditionally. Approximately $10 \pm 0.1 \mathrm{~g}$ of Y-M was weighed, transferred into a $500 \mathrm{~mL}$ beaker. $100 \mathrm{~mL}$ of hot distilled water was added to the Y-M and allowed to remain in contact with the mixture for $1 \mathrm{~min}$. Then using Buchner flask vacuum, samples were filtered and the Y-M residing on the filter paper was further washed with hot water and the final volume was $300 \mathrm{~mL}$. $150 \mathrm{~mL}$ of cyclohexane was added to the $300 \mathrm{~mL}$ aqueous filtrate and stirred for 90 mins using a mechanical shaker and then transferred into a separating funnel. The organic phase was collected and the water phase was discarded. The extract was dried using anhydrous sodium sulphate. Then, the mixture was filtered, and the dehydrated lumps of water were discarded. Finally, a rotary evaporator set at $40^{\circ} \mathrm{C}$ was used to dry the solvent and subsequently the residue was dissolved with a $1 \mathrm{~mL}$ hexane using ultrasonic bath.

b. Soxhlet extraction using hexane

Approximately $10 \pm 0.1 \mathrm{~g}$ of Y-M was weighed. $150 \mathrm{~mL}$ of HPLC-grade hexane. Soxhlet extraction was set up and the cycle lasted for 3 hours then allowed to cool down. Hexane extract was transferred into a $250 \mathrm{~mL}$ conical flask, dried using anhydrous sodium sulphate and filtered. Finally, sample was dried using a rotary evaporator set at $40^{\circ}$ and the residue was dissolved with a $1 \mathrm{~mL}$ HPLC-grade hexane using ultrasonic bath.

c. Soxhlet extraction using distilled water $\left(25^{\circ} \mathrm{C}\right.$ start, $100^{\circ} \mathrm{C}$ end $)$

Approximately $10 \pm 0.1 \mathrm{~g}$ of Y-M was weighed. $150 \mathrm{~mL}$ of water $\left(25^{\circ} \mathrm{C}\right.$ start $)$ was added and soxhlet extraction was used for 3 hours cycle and heated to $100^{\circ} \mathrm{C}$, producing $100 \mathrm{~mL}$ of aqueous extract. Cyclohexane $(100 \mathrm{~mL})$ of was added to $100 \mathrm{~mL}$ of the aqueous extracted. The mixture was stirred for 90 mins using a mechanical shaker then transferred into a separating funnel. The cyclohexane phase was collected, dried using anhydrous sodium sulphate, filtered and finally dried using a rotary evaporator at $40^{\circ} \mathrm{C}$. The residue was dissolved with a $1 \mathrm{~mL}$ HPLC-grade hexane as above.

\subsubsection{GC-MS method development}

The GC-MS analysis was performed with Agilent 6890N gas chromatography (GC) and mass spectrometer-MS (Mass selective detector $5973 \mathrm{~N}$ of Agilent technologies USA). The boiling point of hexane and benzo(b)fluoranthene were the basis of the development. The 
starting and the end temperature for the oven were $100^{\circ} \mathrm{C}$ and $360^{\circ} \mathrm{C}$ with incremental temperature was $5^{\circ} \mathrm{C} / \mathrm{min}$. The equilibrium minute was $0.50 \mathrm{~min}$. Helium was used as a carrier gas and the pressure set at $20 \mathrm{~mL} / \mathrm{min}$. Injection volume was $3 \mu \mathrm{L}$. The mass spectrometer was set up in electronic-impact rate at $70 \mathrm{eV}$ ionisation energy and the machine configured at split mode of 50:1 ratio. A Scan mode as well as selected ion monitoring (SIM) were tried to enhance the detection limit.

\section{Results and discussion}

\subsection{Validation of the GC-MS}

Both scan method and SIM mode were tried, however with scan method irregular background peaks and poor resolution observed probably due to column bleed at a high temperature. Furthermore, concentrations below $5 \mu \mathrm{g} / \mathrm{mL}$ could not be detected using GC-MS scan mode. When switching from scan mode to SIM split-less mode a better signal recovery and peak area since it focused on selected ions of interest (126 and 252). Peaks were auto integrated at eluted time of 33.63 mins that matched the reference retention time of 33.68 mins (Fig. 2).

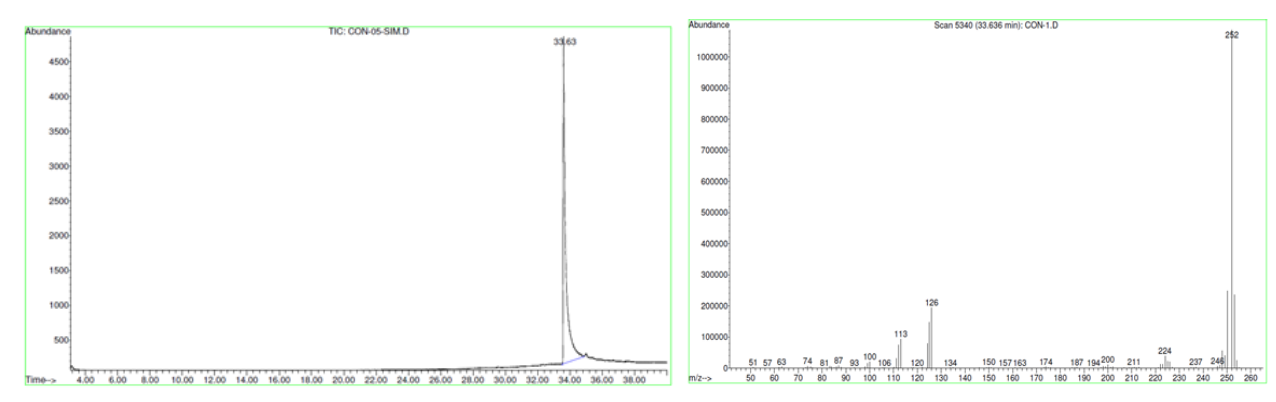

Fig. 2. GC-MS spectrum of Benzo(b)fluoranthene $1(\mathrm{mg} / \mathrm{mL})$ at $\mathrm{SIM}$ mode.

The calibration curve from GC-MS (SIM, split-less mode) showed a good linearity and correlation $\left(\mathrm{R}^{2}=0.99\right)$ between increase in concentration and mean peak areas calculated from triplicate readings $(\mathrm{n}=3)$, Fig. 3. The limit of quantification was calculated as $0.67 \mu \mathrm{g} / \mathrm{mL}$ and the limit of detection was $0.22 \mu \mathrm{g} / \mathrm{mL}$.

\subsection{Extraction methods}

The effect of the method of extraction on the yield is given in Table 1. The extraction using hexane gave the highest yield which can be explained as PAHs are nonpolar compounds and dissolve better in hexane as an organic solvent and also this extraction method involved constant heating coupled with less filtration. However, the extraction using hot distilled water as a solvent, which gave a lower yield, simulates the way of making and drinking Yerba-maté which suggested it resembles the PAH intake while drinking this herbal infusion. 


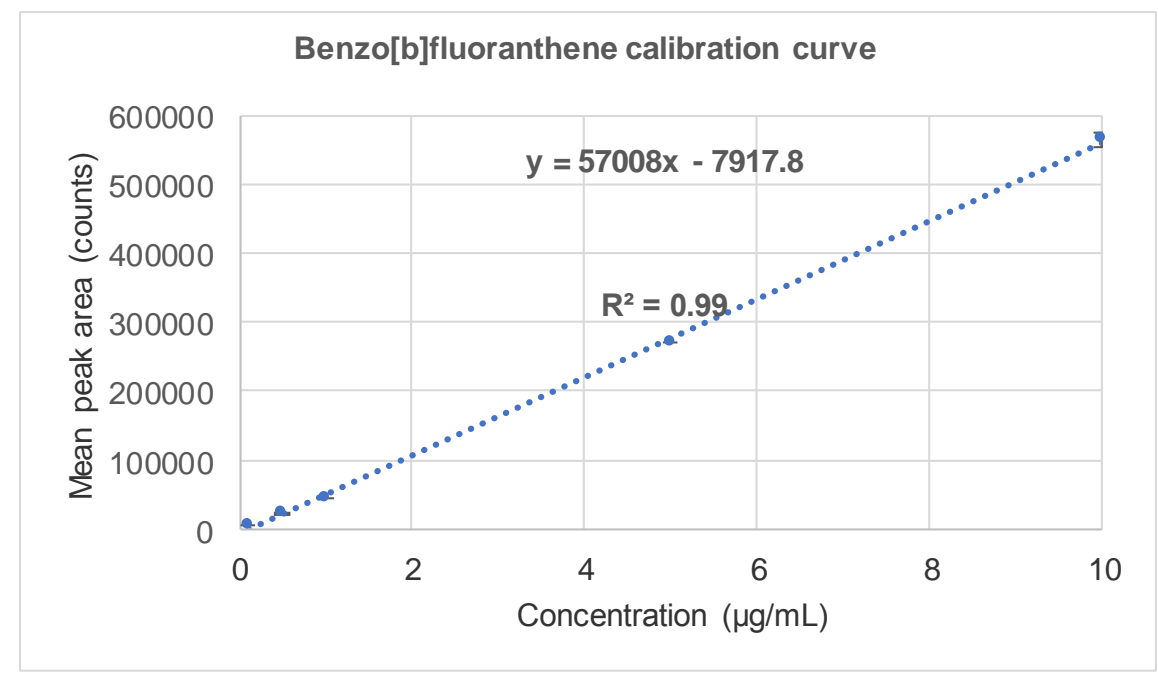

Fig. 3. Benzo(b)fluoranthene calibration curve of mean peak area (counts) against concentration $(\mu \mathrm{g} / \mathrm{mL})$ from GC-MS (SIM, split-less mode), $\mathrm{n}=3$.

The developed GC-MS-selected ion monitoring (SIM) is a technique that provides good specificity and sensitivity in which only the selected mass to charge ratio $(\mathrm{m} / \mathrm{z})$ is detected instead of the entire spectrum in a mass spectrometer. In the current method, the focused ions were 126 and 252 (main ion). The results obtained here are in accordance with a study [4] that was carried out using selected single ion monitoring focusing on 126 ion, 250 ion and $252 \mathrm{ion}$, the previous study reported limit of detection of $0.25 \mu \mathrm{g} / \mathrm{kg}$ as well as limit of quantification $0.5 \mu \mathrm{g} / \mathrm{kg}$. It is important to note that the level detected.

Table 1. the concentrations of benzo(b)fluoranthene $(\mu \mathrm{g} / \mathrm{g})$ extracted from Yerba-maté using different extraction methods and their corresponding peak area (counts).

\begin{tabular}{|c|c|c|}
\hline Method of extraction $(\mathbf{1 0} \pm \mathbf{0 . 1} \mathbf{g}$ Yerba-maté) & $\begin{array}{c}\text { Peak area } \\
(\mathbf{c o u n t s})\end{array}$ & $\begin{array}{c}\text { Benzo(b)fluoranthene } \\
(\boldsymbol{\mu g} / \mathbf{g})\end{array}$ \\
\hline $\begin{array}{c}\text { Extraction using hot distilled water } \\
\left(70-90^{\circ} \mathrm{C}\right) \text { as a solvent }\end{array}$ & 3236 & 0.02 \\
\hline $\begin{array}{c}\text { Soxhlet extraction using distilled water }\left(25^{\circ} \mathrm{C}\right. \\
\text { start, } 100^{\circ} \mathrm{C} \text { end) as a solvent }\end{array}$ & 15022 & 0.04 \\
\hline $\begin{array}{c}\text { Soxhlet extraction using hexane }\left(25^{\circ} \mathrm{C} \text { start, }\right. \\
68^{\circ} \mathrm{C} \text { end) as a solvent }\end{array}$ & 43664 & 0.09 \\
\hline
\end{tabular}

\section{Conclusion}

In conclusion, the developed extraction method using hot distilled water as a solvent, soxhlet extraction using both distilled water and hexane as a solvent and GC-MS selected ion monitoring (SIM) gave a yield benzo(b)fluoranthene ranging from 0.02 to $0.09 \mu \mathrm{g} / \mathrm{g}$ 
from $10 \pm 0.1 \mathrm{~g}$ Yerba-maté commercial samples. GC-MS (SIM Split-less mode) indicated a good repeatability of the peak area while there was a strong correlation and linearity between mean peak area and concentration from the calibration curve. Furthermore, GC-MS SIM split-less mode enhanced the chromatogram and peak area up to 50-fold compared to scan mode. The developed method are relatively simple for the determination of trace levels of polyaromatic hydrocarbons PAH in dried Yerba-maté leaves that could possibly be employed on other types of food. Future work will include the determination of the occurrence of the three remaining PAHs polyaromatic hydrocarbons (benzo[a]pyrene, benzo[a]anthtracene, and chrysene) in wider level of commercial Yerba-maté herbal drink and finally compare the results against food safety requirements to see if the marketed products meet the level allowed in terms of the $\sum$ PAH4.

\section{References}

1. C. I. Heck, E. G. De Mejia, J. Food Sci. 72, 138-51 (2007)

2. D. Hao, X. Gu, P. Xiao, Z. Liang, L. Xu, Y. Peng, Acta Pharm. Sin B 3, 8-19 (2013)

3. M. Ali, S. Horikawa, S. Venkatesh, J. Saha, J. W. Hong, M. E. Byrne, J. Control Release 124, 154-62 (2007)

4. Z. Zelinkova, T. Wenzl, Food Addit. Contam. Part A 32, 1914-26 (2015) 